\title{
Acceptable levels for the breathing resistance of respiratory apparatus: results for men over the age of 45
}

\author{
R. G. LOVE 1 , D. C. F. MUIR ${ }^{1}$, K. F. SWEETLAND ${ }^{1}$, R. A. BENTLEY ${ }^{2}$, AND \\ O. G. GRIFFIN ${ }^{2,3}$
}

From the Institute of Occupational Medicine, Edinburgh, Scotland ${ }^{1}$, and Safety in Mines Research Establishment, Sheffield, England ${ }^{2}$

\begin{abstract}
Tolerance of additional external resistance to inspiration has been investigated in a group of coalworkers older than $\mathbf{4 5}$ years. Peak inspiratory pressure, external respiratory work rate, ventilation, and gas exchange were measured, during periods with and without one of four inspiratory resistances, on 41 subjects walking on a treadmill. Minute volume was reduced, breathing frequency was unchanged and oxygen uptake and carbon dioxide elimination were reduced by the presence of resistance. It was established that, at the workload studied, older men were able to tolerate inspiratory resistance to at least the same extent as younger men, when the respiratory work was expressed in terms of unit ventilation. It is suggested that the acceptable level of breathing resistance established for younger men can also be applied to older workers.
\end{abstract}

An acceptable level of inspiratory resistance for subjects used to wearing breathing apparatus has recently been established, following investigation of the tolerance limits of 158 coalworkers (Bentley et al., 1973). These men were all under 45 years of age, either full-time or part-time mine-rescue workers, with above-average physical fitness. Previous investigators (Silverman et al., 1943; 1945) had derived standards for external respiratory resistance based on measurements made on young men untrained in the use of breathing apparatus.

Underground workers in the British coal industry are issued with a 'self-rescuer' apparatus for removing carbon monoxide produced by fire or explosion, from the inspired air during their escape to uncontaminated air. Many of these men are over 45 years old, not as physically fit and in some cases possibly not so able to tolerate as high a resistance to breathing, as younger men. We therefore decided to investigate the level of inspiratory resistance acceptable to a group of older coalworkers and to

so. G. Griffin died 5 January 1976

Received for publication 26 May 1976 Accepted for publication 12 August 1976 determine whether or not a different standard of resistance should be applied to such men.

In a previous paper (Bentley et al., 1973) a standard was suggested such that $90 \%$ of a population, breathing through apparatus with low expiratory resistance, would experience no discomfort if the mean inspiratory work rate did not exceed $1.37 \mathrm{~J}^{-1}$. The results of a similar study conducted on a group of older men are discussed in this paper. The effects of resistance on ventilation and gas exchange are also described and compared with a control period.

\section{Methods}

The experimental apparatus was similar to that described elsewhere (Bentley et al., 1973). In addition a length of wide-bore, low-resistance tubing was connected to the expiratory valve of the mouthpiece assembly, so that expired air passed through a 10 litre mixing bottle. A continuous sample was drawn from this bottle through a drying agent to a fast-response oxygen analyser (Beckman Model E2 rapid-response analyser) and a katharometer (GowMac Model 20-100) linked to a potentiometric chart recorder (Honeywell, class 19), which gave a con- 
tinuous read-out of carbon dioxide concentration in the mixed expired air.

Inspired volumes were recorded by means of a respiratory anemometer (Wright, 1955). Frequency of breathing and peak pressures at the mouth were measured with a water manometer and a differential pressure transducer (Greer micromanometer, Type M3, Capsule Type A 1000) connected to an ultraviolet light recorder (S.E. 2005).

Four inspiratory resistances were used in the experiments. Their construction and pressure/flow characteristics have been described previously (Bentley et al., 1973). The airflow characteristics were non-linear, in order to simulate those of most industrial breathing equipment. The pressure drop across the resistances $\mathrm{R} 1, \mathrm{R} 2, \mathrm{R} 4$ and $\mathrm{R} 6$ was $0.4,1.0,1.7$ and $2.4 \mathrm{kPa}$ respectively at a constant airflow of $1001 \mathrm{~min}^{-1}$.

The experimental subjects consisted of 41 men, randomly selected from all underground workers aged 45 years and over at a Yorkshire colliery (Table 1). Five of the men had been classified radiologically as suffering from category 1 and five from category 2 simple pneumoconiosis. This proportion of pneumoconiotics is slightly greater than the prevalence rate of the disease in miners of this age group working in the same area.

The subjects, who all participated voluntarily, were required to walk on a treadmill at $70 \mathrm{~m} \mathrm{~min}^{-1}$ up a $9 \%$ incline to simulate an average walking task underground (Hadden et al., unpublished results). Each man wore normal working clothes, boots and safety helmet and carried a cap lamp and battery. Before the test he took a short practice walk on the treadmill. For the first 15 minutes of exercise no inspiratory resistance, other than that of the mouthpiece, valves and tubing, was inserted in the apparatus. At the end of this period the subject was stopped, the resistance was inserted and a further 15 minutes of exercise was begun. The interval between each exercise period was approximately one minute. Although each subject was told that a resistance was to be added during the second period, its magnitude was not specified.

During the first three minutes of each period the subject was allowed to reach a steady state. The total volume inspired during the next 12 minutes was then recorded and breathing frequency, peak pressures, expired oxygen and carbon dioxide concentrations were recorded during this period at intervals of one minute.

At the end of the experiment the subject was asked to choose from a card one of four conditions that most closely described his sensation of breathing through the added resistance compared with that of the control period. Intermediate responses were also accepted from men who felt that the choice was too restricted.

\section{Results}

The average minute volumes of air achieved by each group of subjects were just over $401 \mathrm{~min}^{-1}$ at a mean oxygen uptake of $75 \mathrm{mmol} \mathrm{min}-1$ during control breathing without added inspiratory resistance. $\dot{V}_{\mathbf{E}}$ (expired minute volume) was related to the body weight but not to the age of the subjects. Only two subjects experienced sufficient discomfort to give an adverse response following resistance breathing, one at each of the two highest resistances. Both of these men had simple pneumo-coniosis. All other subjects found that the breathing resistance was either not detectable, or noticeable but not difficult. However, two subjects experienced difficulty in holding the mouthpiece in position.

The ventilation and gas exchange data for each group, before and after the appropriate inspiratory resistance was introduced, are shown in Table 2. Mean values, standard deviations and differences between control and resistance breathing are given. There was a small but statistically significant fall in $\dot{\mathrm{V}}_{\mathbf{E}}$ with all but the lowest resistance, but the breathing rate was virtually unchanged. The proportion of the breathing cycle spent on inspiration (I) increased progressively as resistance increased $(P<0.001)$, so that inspiration consisted of over $56 \%$ of each breath on average for the highest resistance compared with the control value of $42-46 \%$. Oxygen uptake and $\dot{\mathrm{V}}_{\mathrm{CO}_{2}}\left(\mathrm{CO}_{2}\right.$ production per minute) were reduced at each resistance level but $\mathrm{FE}_{\mathrm{CO} 2}$ and

Table 1 Characteristics of subjects

\begin{tabular}{|c|c|c|c|c|c|c|}
\hline \multirow[t]{2}{*}{ Group resistance } & \multirow[t]{2}{*}{ No. of subjects } & \multirow[t]{2}{*}{ Mean age $(y r)$} & \multirow[t]{2}{*}{ Mean weight $(\mathrm{kg})$} & \multicolumn{3}{|c|}{ No. of subjects in pneumoconiosis category } \\
\hline & & & & 0 & 1 & 2 \\
\hline $\begin{array}{l}\text { R1 } \\
\text { R2 } \\
\text { R4 } \\
\text { R6 }\end{array}$ & $\begin{array}{r}8 \\
6 \\
12 \\
15\end{array}$ & $\begin{array}{l}54 \cdot 3(5 \cdot 7) \\
53 \cdot 8(5 \cdot 2) \\
53 \cdot 3(4 \cdot 0) \\
52 \cdot 6(4 \cdot 7)\end{array}$ & $\begin{array}{l}75 \cdot 6(12 \cdot 4) \\
78 \cdot 7(9 \cdot 6) \\
73 \cdot 6(10 \cdot 1) \\
77 \cdot 6(12 \cdot 3)\end{array}$ & $\begin{array}{r}4 \\
4 \\
10 \\
13\end{array}$ & $\begin{array}{l}2 \\
1 \\
1 \\
1\end{array}$ & $\begin{array}{l}2 \\
1 \\
1 \\
1\end{array}$ \\
\hline Total & 41 & $53.3(4.9)$ & $76.2(11.5)$ & 31 & 5 & 5 \\
\hline
\end{tabular}

SD in parentheses. 
Table 2 Exercise ventilation and gas exchange during a control period $(C)$ and with an inspiratory resistance $(R)$

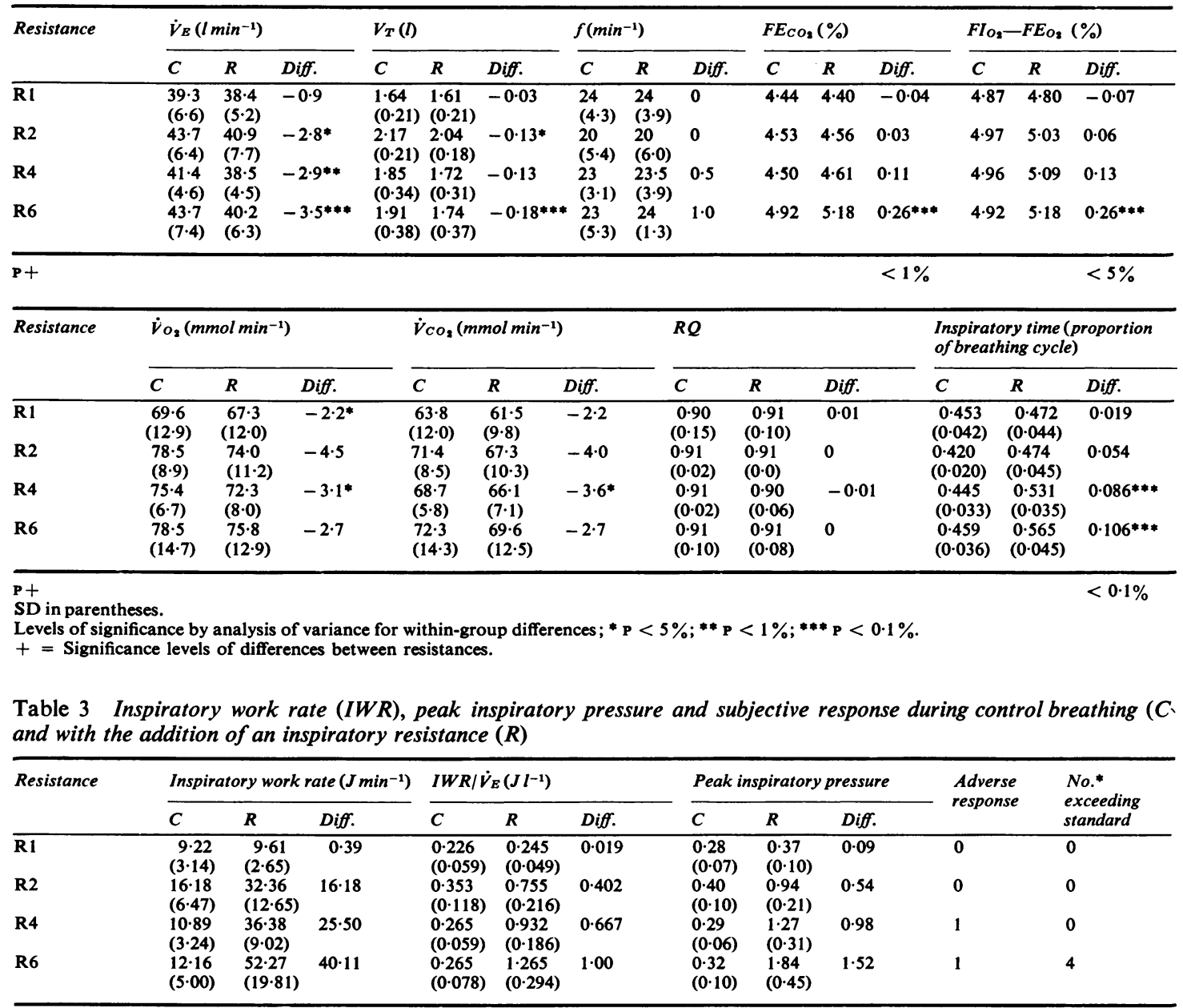

SD in parentheses.

*Number of men whose inspiratory work rate exceeded $1 \cdot 37 \mathrm{~J}^{-1}\left(0 \cdot 14 \mathrm{~kg} \mathrm{l}^{-1}\right)$. (Bentley et al., 1973).

FIo2-FE02 were larger with the two highest resistances. There was no overall change in RQ.

Peak inspiratory pressure and inspiratory work rate per litre of ventilation during control and resistance breathing are illustrated in Table 3.

\section{Discussion}

Tolerable levels of inspiratory resistance have previously been established in a group of fit minerescue workers aged less than 45 years (Bentley et al., 1973). However, many underground workers in collieries are older than this and may be partially disabled either by pneumoconiosis or by some other respiratory or circulatory disorder. Evidence pre- sented here suggests that such men are able to tolerate breathing resistances as high as those tolerated by their younger colleagues.

Only four subjects breathing through the highest resistance had an average inspiratory work rate, per litre of air breathed, greater than $1.37 \mathrm{~J} \mathrm{I}^{-1}$, the level below which $90 \%$ of younger men are unlikely to experience discomfort. None of these four men reported subjective discomfort. Two other men, both with pneumoconiosis, complained that breathing was difficult when the inspiratory work load was below this level. This distribution is compatible with results obtained with younger subjects, as 34 out of 36 men $(95 \%)$ did not experience any discomfort when the work load was 
below this level. This group of older men, therefore, is able to tolerate at least as high a resistance to breathing as younger men, and there is no firm evidence from this study that pneumoconiotics are more susceptible to the effects of resistance to breathing.

The work rate and highest breathing resistance employed in this study fell in the mid-range of those used in the study of younger subjects. However, that study indicated that the inspiratory work rate per litre of air breathed determines the level of discomfort. If this level is not exceeded then not more than $10 \%$ of that population should experience discomfort while breathing through a resistance.

The four subjects with inspiratory work rates greater than $1.37 \mathrm{~J}^{-1}$ who had no difficulty in breathing through the resistance, were all heavier and had minute volumes greater than the average. However, the inspiratory work rate per litre of air breathed still includes a factor for minute volume in the numerator of the equation used in its calculation, that is, $\mathrm{Wi} / 1=\mathrm{A} \mathrm{V}_{\mathbf{E}} \mathbf{n} / \mathbf{I}^{\mathrm{n}}$ where $\mathrm{A}$ is a constant and $\mathrm{n}$ is a number depending on the shape of the waveform. Hence men with larger minute volumes will on average tend to have greater inspiratory work rates, although these work rates may not be inappropriate for the volumes of air breathed by these particular men.

There is evidence from the literature that older men need not necessarily be handicapped during physical exercise, as the average minute volume of an older man is likely to be similar to that of younger men (Robinson, 1938).

Early coalworkers' simple pneumoconiosis does not usually give rise to significant changes in lung function; men with such a condition (ten in the present study) are therefore unlikely to be at a physical disadvantage compared to their nonpneumoconiotic colleagues (Cotes, 1975).

The resistances employed in this study only marginally affected the breathing pattern. The minute volume was reduced by only $8 \%$ even at the highest resistance, which is of the same order as the data of Silverman et al. (1945) and in agreement with the findings of Cerretelli et al. (1969) and Craig et al. (1970) during more strenuous exercise. As breathing frequency was unchanged by the presence of any resistance the fall in tidal volume was the main cause of the reduced ventilation rate. The pattern of breathing altered, however, and inspiration occupied a greater proportion of the breathing cycle with the higher resistances.

The low resistances used in the experiments had only a marginal effect on respiratory gas exchange. Both $\dot{\mathrm{V}}_{\mathrm{O}_{2}}$ and $\dot{\mathrm{V}}_{\mathrm{CO}_{2}}$ fell slightly but the amount of change was not related to the value of the inspiratory resistance. The changes in $\dot{\mathrm{V}}_{\mathrm{CO}_{2}}$ and $\dot{\mathrm{V}}_{\mathrm{O}_{2}}$ appeared to be of the same order and there was no change in RQ. Our findings are at variance with Silverman et al. (1945) who found an increase in oxygen uptake in subjects breathing through inspiratory resistances. However they agree with findings of Killick (1935) who observed a fall in carbon dioxide output and oxygen uptake in some of her subjects.

It is concluded that the level of resistance that could be tolerated by men older than 45 years of age should be the same as the standard suggested for younger men (Bentley et al., 1973). This standard states that $90 \%$ of a population will not experience respiratory discomfort if the inspiratory work per litre of air inhaled does not exceed $1.37 \mathrm{~J}^{-1}$.

The breathing resistance of the present selfrescuer apparatus used in British collieries is equivalent to about $0.98 \mathrm{~J}^{-1}$ and hence falls well within this standard. These results could be applied to all workers likely to have to wear emergency breathing apparatus but should not be accepted as tolerable limits for men wearing dust or gas masks for longer periods.

The authors thank M. D. Attfield for his assistance with statistical calculations.

\section{References}

Bentley, R. A., Griffin, O. G., Love, R. G., Muir, D. C. F., and Sweetland, K. F. (1973). Acceptable levels for breathing resistance of respiratory apparatus. Archives of Environmental Health, 27, 273-280.

Cerretelli, P., Sikand, R. S., and Farhi, L. E. (1969). Effect of increased airway resistance on ventilation and gas exchange during exercise. Journal of Applied Physiology, 27, 597-600.

Cotes, J. E. (1975). Lung Function, 3rd edn, p. 450. Blackwell: Oxford.

Craig, F. N., Blevins, W. V., and Cummings, E. G. (1970). Exhausting work limited by external resistance and inhalation of carbon dioxide. Journal of Applied Physiology, 29, 847-851.

Killick, E. M. (1935). Resistance to inspiration-its effects on respiration in man. Journal of Physiology, 84, 162-172.

Robinson, S. (1938). Experimental studies of physical fitness in relation to age. Arbeitsphysiologie, 10, 251-323.

Silverman, L., Lee, R. C., Lee, G., Drinker, K. R., and Carpenter, T. M. (1943). Fundamental factors in the design of respiratory equipment: inspiratory airflow measurements on human subjects with and without resistance. Bulletin 1222. Office of Scientific Research and Development: Washington, D.C.

Silverman, L., Lee, G., Yancey, A. R., Amory, L., Barney, L. J., and Lee, R. C. (1945). Fundamental factors in the design of respiratory equipment-a study and an evaluation of inspiratory and expiratory resistances for protective respiratory equipment. Bulletin 5339. Office of Scientific Research and Development: Washington, D.C.

Wright, B. N. (1955). A respiratory anemometer. Journal of Physiology, 127, 25P. 